STUDI

FRANCESI
Studi Francesi

Rivista quadrimestrale fondata da Franco Simone

146 (XLIX | II) | 2005

Varia - fasc. II - maggio-agosto 2005

\title{
Mary Gallagher (ed.), Ici-là. Space and displacement in Caribbean writing in French
}

\section{Anusca Ferrari}

\section{(2) OpenEdition}

Journals

\section{Édition électronique}

URL : http://journals.openedition.org/studifrancesi/35327

DOI : 10.4000/studifrancesi.35327

ISSN : 2427-5856

Éditeur

Rosenberg \& Sellier

\section{Édition imprimée}

Date de publication : 1 novembre 2005

Pagination : 461-462

ISSN : 0039-2944

\section{Référence électronique}

Anusca Ferrari, « Mary Gallagher (ed.), Ici-là. Space and displacement in Caribbean writing in French », Studi Francesi [En ligne], 146 (XLIX | II) | 2005, mis en ligne le 30 novembre 2015, consulté le 18 avril 2021. URL : http://journals.openedition.org/studifrancesi/35327 ; DOI : https://doi.org/10.4000/ studifrancesi.35327

Ce document a été généré automatiquement le 18 avril 2021.

\section{(c)}

Studi Francesi è distribuita con Licenza Creative Commons Attribuzione - Non commerciale - Non opere derivate 4.0 Internazionale. 


\title{
Mary Gallagher (ed.), Ici-là. Space and displacement in Caribbean writing in French
}

\author{
Anusca Ferrari
}

\section{RÉFÉRENCE}

MARY GALLAGHER (ed.), Ici-là. Space and displacement in Caribbean writing in French, Amsterdam, Rodopi, 2003, pp. 308.

1 L'un des thèmes récurrents des littératures postcoloniales est le rapport du sujet avec l'espace. La colonisation a isolé les populations indigènes et imposé un rapport hiérarchique entre colonisateur et colonisé, créant ainsi une rupture dans le lien identitaire avec l'espace. Ce processus a été particulièrement douloureux aux Antilles, puisque la population a été déportée. La réaction pathologique à la colonisation s'exprime dans un sens de «déplacement» du sujet postcolonial, dû au dénigrement subi par l'oppresseur. Les treize articles ici présentés traitent les thèmes du déplacement et du lieu comme caractéristiques du discours postcolonial antillais; ce volume fait suite à un colloque qui s'est tenu à Dublin en 1999. Mary Gallagher, qui enseigne à l'University College (Dublin), dans l'introduction explique l'idée de déplacement en questionnant le syntagme créole «ici-là», qui apparaît dans plusieurs textes antillais. Ce déictique paraît signaler, selon Gallagher, le rapport complexe avec l'espace dans la société antillaise, rapport qui implique aussi un questionnement du temps. Le premier article a été écrit par Ernest Pépin, écrivain guadeloupéen, qui analyse le rôle de l'espace dans le mouvement littéraire de la créolité. L'auteur retrace une histoire de la littérature de la Guadeloupe e de la Martinique par le biais de la spatialité, en distinguant trois phases fondamentales: la première, la phase de l'exotisme, la deuxième celle des mornes et la troisième, celle de la ville. Le Cahier de Césaire représente le premier texte de rupture avec la tradition doudouiste et engage la littérature antillaise dans la problématique de l'espace. À partir de ce texte, Pépin 
présente une poétique de la résistance dans le rapport entre personnages et paysages ruraux ou urbains - dans les œuvres de Édouard Glissant, Simone Schwartz-Bart, Patrick Chamoiseau, Ernest Pépin, Raphaël Confiant et Gisèle Pineau. Les trois articles qui suivent considèrent l'œuvre de Chamoiseau. Roy Chandler Caldwell, professeur à la St. Lawrence University (Usa), reprend l'importance de la ville créole dans Texaco de Patrick Chamoiseau. L'auteur de cet article construit un parallèle entre l'urbanisation en Europe et aux Antilles, expliquant les implications idéologiques et historiques de la construction d'un ghetto comme Texaco, qui représente la mise en question de l'organisation politique occidentale et de sa conception cartésienne de l'espace. MarieSophie, protagoniste du roman, nie la mondialisation et relie l'espace de la ville au passé et à la culture locale. Le même roman est étudié par Maeve McCusker (St Queen University, Belfast) qui voit dans la maison le symbole d'une immobilité, antonyme de l'idée de déplacement dont Marie-Sophie se fait porteuse. La construction de la maison acquiert une charge métaphorique et est parallèle à la constitution de l'identité, mais aussi avec le rapport oralité-écriture qui caractérise la littérature antillaise. McCusker signale que le désir de la solidité du ciment et du livre écrit symbolise la mort de la culture créole, dans une stabilité qui est «a state which metonymically gestures toward the condition of the assimilated island itself» (p. 59). Le rapport de Chamoiseau avec l'écriture est interrogé aussi dans l'article de Lorna Milne, professeur à la St Andrews University. L'étude porte sur L'esclave vieil homme et le molosse et le parallèle entre l'espace du marronnage et de l'écriture. Le changement du paysage dans la narration équivaut à quatre étapes de changement de l'identité de l'esclave, la phase finale étant celle de l'affirmation du moi. Le récit est perçu en même temps comme manifestation du déplacement dans le style. La narration, qui glisse du «il» au «je», crée une projection du narrateur dans la figure de l'esclave. Ainsi, le marron et le marqueur ne sont pas deux figures dichotomiques, mais représentent deux facettes de la même poétique.

2 Le cinquième et le sixième article étudient l'œuvre d' Édouard Glissant. Celia Britton, professeur à l'Université d'Aberdeen, examine le traitement de l'espace dans Mahogany. Le rapport qu'elle décèle entre espace et temps est hyperbolique: chaque lieu est le symbole d'un ou plusieurs événements, qui se superposent et rendent le paysage hypersymbolique. Le texte résonne de cette symbolisation, et on retrouve un parallèle lexical et structural entre les deux parties du roman «Remontée» et «Descente». Bernadette Cailler, par contre, considère Glissant en tant que poète et analyse le Sel noir et Les Grands Chaos, en montrant le rapport de distanciation et de rapprochement au lecteur mis en place par le narrateur et les liens intertextuels avec d'autres écrits francophones. Le septième article est de Maximilien Laroche, professeur de littérature à l'Université de Laval, et analyse le déplacement mental dans trois romans haïtiens, à savoir Gouverneurs de la rosée de Jacques Roumain, Les arbres musiciens de Jacques Stephen Alexis et Pays sans Chapeau de Dany Laferrière. Les deux premiers textes ont une vision de la nation, de la terre et de la culture haïtienne qui est assez semblable, tandis que le roman de Laferrière propose un regard neuf et ironique sur Haïti. Martin Munro, qui enseigne à l'Université de West Indies (Trinidad), dans son étude comparée de Aimé Césaire et René Depestre, fouille le rapport des deux écrivains avec la Caraïbe, l'Europe et l'Afrique. Césaire, qui situe son œuvre aux Antilles, voit son île comme un lieu vide qu'il essaie de remplir par d'autres espaces, notamment l'Afrique et le rapport de dépendance avec l'Europe, tandis que Depestre est enraciné dans la Caraïbe. Le triangle Caraïbe-Afrique-Europe est évoqué aussi dans l'article de Mary Gallagher, qui 
compare Passages d'Émile Ollivier à Tambour-Babel d'Ernest Pépin, le premier étant un roman de l'aliénation et de l'impossibilité de replacement de l'individu, le deuxième qui trouve une harmonie entre ces lieux de référence. L'article de Charles Forsdick stipule une relation entre le château de Joux, en France, et l'histoire des Antilles. Toussaint Louverture était prisonnier dans un cachot de la prison de Joux et l'endroit revient dans de nombreux ouvrages antillais. Beverly Ormerod, professeur à l'University of Western Australia, propose une lecture des déplacements émotifs dans les romans de Gisèle Pineau. Le déplacement dans son œuvre se manifeste souvent par un exil, ou par une marginalisation, ou encore par une violence subie souvent par des femmes. Kathleen Gyssels, professeur à l'Université d'Anvers, étudie le rôle de la distance dans la pièce théâtrale Ton beau capitaine de Simone Schwartz-Bart. La forme allégorique est comparée au théâtre Nō traditionnel. Enfin, Nick Coates examine la théorie du chaos appliquée à Édouard Glissant et Patrick Chamoiseau. Les différents articles de ce volume montrent la complexité du rapport entre espace et littérature caribéenne francophone et interprètent le déplacement dans ses implications positives: le déplacement est aussi relation et ouverture, idées qui sont centrales pour une étude de la littérature antillaise. 